\title{
Centro de Interpretación de la Diversidad Cultural de Jauja, Junín - Perú
}

\author{
Center for the interpretation of cultural diversity in Jauja, Junín - Peru
}

Ana María Lebrún Aspillaga ${ }^{1}$

\section{RESUMEN}

El Centro de Interpretación de la Diversidad Cultural de Jauja se plantea como una institución que promueve e incentiva situaciones de conocimiento y la difusión del legado histórico y cultural de la provincia de Jauja, donde se genere identidad con la historia y el patrimonio existente material $e$ inmaterial, con la participación comunitaria de sus habitantes, para sentirse identificados, permitiendo de esta manera la mejora dentro del ámbito social, cultural, económico y del medio ambiental en el cual se inserta.

A través del patrimonio natural y cultural de Jauja, se brinda las claves y herramientas necesarias para hacer comprensible el objeto patrimonial y el contexto en el que aparece, promoviendo el uso y consumo los productos turísticos de la zona en este espacio, que permitirá a los visitantes deseos de conocer el territorio y todo lo que en él se encuentra.

El planteamiento general de la museografía está basado en brindar diversas sensaciones y emociones al visitante, como un espacio de comunicación, con elementos de carácter lúdico, mediante un lenguaje fácil y comprensible de entender, incluyendo un trabajo sistematizado de enseñanza-aprendizaje a través de la educación formal, no formal e informal.

\section{Palabras clave}

Centro de Interpretación, Centro de Interpretación de Jauja, Diversidad Cultural de Jauja.

\begin{abstract}
The Center for Interpretation of Cultural Diversity in Jauja is considered as an institution which promotes knowledge and dissemination of the historical and cultural legacy of Jauja's provinces, where identity is consolidated with history, existing material and immaterial heritage, with the community participation of its inhabitants, to feel identified, promoting in this way the improvement within the social, cultural, economic and environmental areas in which it is inserted.
\end{abstract}

Through the natural and cultural heritage in Jauja provides the necessary keys and tools to make understandable the patrimonial object and the context in which it appears, promoting the use and consumption of tourism products of the area in this space that will allow visitors expectations to know the territory and all that is in it.

The general approach of the museography is based on providing different sensations and emotions to the visitor, as a space of communication, with elements of playful character, through an easy and comprehensible language, including a systematized work of teaching-learning through formal, non-formal and informal education.

\section{Keywords}

Center of Interpretation, Center of Interpretation in Jauja, cultural diversity of Jauja.

1 Arquitecta. Magíster en Museología. Past Directora de museos y gestión del patrimonio histórico del Instituto Nacional de Cultura y del Museo Postal y Filatélico del Perú. Gerente General de RUTA 4 SAC Planificación y Acción Cultural. Vicepresidenta y Directora de Proyectos Nacionales e Internacionales de Instituto RUTA 4 Investigación y Proyectos. 


\section{INTRODUCCIÓN}

La propuesta del Centro de Interpretación de la Diversidad Cultural de Jauja se plantea como un espacio de interacción y comunicación para la comunidad en general, así como a los visitantes locales, regionales, nacionales $e$ internacionales, donde se articula la historia y tradición jaujina con las diversas rutas turísticas de la provincia de Jauja, lo cual generará identidad entre los visitantes y con lo puesto en el centro de interpretación.

Jauja, la primera capital del Perú, presenta inadecuados servicios turísticos para los visitantes que llegan a la ciudad, impidiendo que se llegue a conocer y apreciar los atractivos turísticos existentes en la zona como la Plaza de Armas, la arquitectura de la zona monumental, la iglesia matriz y la Capilla Cristo Pobre. Esto se ve acentuado por la deficiente orientación turística y la carencia de guías turísticos que puedan orientar y guiar adecuadamente a los visitantes. Asimismo, no cuenta con un espacio cultural donde se brinde información de la ciudad, sus atractivos y el patrimonio cultural y natural existente en la región Jauja.

El Centro de Interpretación pretende comunicar el significado de la diversidad cultural de Jauja a través de un lenguaje sencillo, claro, ameno, directo y de fácil comprensión para los visitantes, utilizando los recursos museográficos idóneos, generando identidad y apropiación entre todos sus habitantes. Asimismo, pretende revalorar la memoria colectica; mostrar la riqueza cultural donde reside su diversidad dialogante; desarrollar programas de educación y actividades de divulgación cultural $y$; finalmente, generar emoción y curiosidad en el visitante.

Teniendo en cuenta la diversidad cultural en Jauja, es relevante presentar el patrimonio material e inmaterial, abarcando la historia desde un aspecto general para el conocimiento de los visitantes y su adecuada contextualización. Asimismo, el patrimonio material se ve reflejado en el patrimonio monumental de Jauja, así como en las manifestaciones artísticas contemporáneas como el muralismo, la artesanía y las artes plásticas. En cambio, el patrimonio inmaterial se ve reflejado en la diversidad de danzas y fiestas tradicionales existentes y la cultura popular mediante la religiosidad popular y la cultura viva, así como la diversidad de cuentos populares que revaloran la tradición oral que ha perdurado a lo largo de los años.

Las estrategias narrativas para el Centro de Interpretación han sido focalizadas para generar una idea central clara con un lenguaje sencillo y comprensible; exponer y comunicar el patrimonio material e inmaterial mediante recursos museográficos bidimensionales y tridimensionales con carácter lúdico de toda la muestra museográfica; generar conexiones intelectuales y emocionales, estimulando el pensamiento crítico de parte del visitante, lograr que el visitante se identifique con el patrimonio cultural y natural de la provincia de Jauja, permitiendo de esta manera una adecuada difusión, informando sobre la diversidad de los valores culturales; proporcionar un alto nivel de conciencia por parte de la población y ; permitir que los visitantes logren captar el significado del sitio, tradiciones y prácticas culturales.

El público objetivo estará conformado por todo tipo de visitantes, es decir, va a estar destinado a los niños, adolescentes, jóvenes, adultos $y$ adultos mayores.

\section{HISTORIA Y ARQUITECTURA}

La Plaza de Armas de Jauja fue declarada como ambiente urbano monumental mediante R.J. N. ${ }^{\circ} 515$ del 12 de agosto de 1989, debido a que posee elementos de valor urbanístico que deben conservarse total o parcialmente. Igualmente, mediante RDN 906/INC del 17 de diciembre de 2003 se declara la Zona Monumental de Jauja la zona donde se encuentra la Plaza de Armas, la Municipalidad Provincial, entre otras manzanas.

El actual emplazamiento de Jauja data de 1565, con el trazo característico de las ciudades españolas, con calles rectangulares a manera de tablero de ajedrez, surgiendo los edificios más importantes de la ciudad, como la iglesia, el local del Cabildo y las casonas de esa época, que se ubicaban, casi todas, en la Plaza Mayor. De este momento fundacional, lo 
que ha quedado a lo largo del tiempo es la Iglesia Matriz, ya que el local del Cabildo se derrumbó a principios del siglo XX (Gobierno Regional de Lima, 2010).
El primer testimonio gráfico de la plaza es del año 1838 y fue realizado por el Vicecónsul francés Léonce Angrand, donde se aprecia el Cabildo de Jauja (Hurtado, s/f).

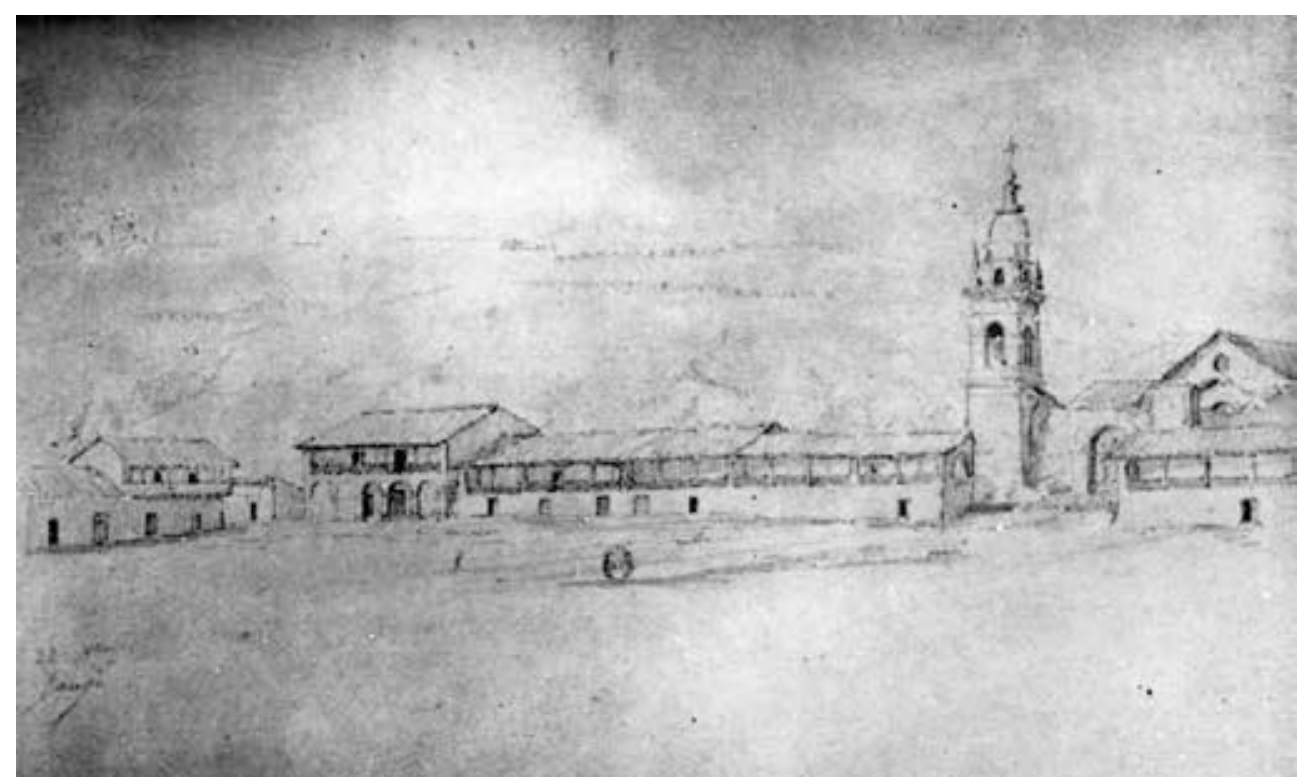

Figura 1. La Plaza de Jauja hacia 1838 de acuerdo al dibujo de Léonce Angrand. (Recuperado de Hurtado, s/f).

Hacia mediados del siglo XIX y de acuerdo a la referencia de los viajeros, en la plaza se realizaban las principales fiestas, corridas de toros y escenario de disputas entre los indios, tal como lo hiciera el viajero alemán Tschudi en 1840. El viajero estadoudinense Gibbon, indica que, en la plaza, las mujeres venden sus productos para la despensa y el domingo se transformaba en una gran feria, ya que llegaban los indios. (Hurtado).

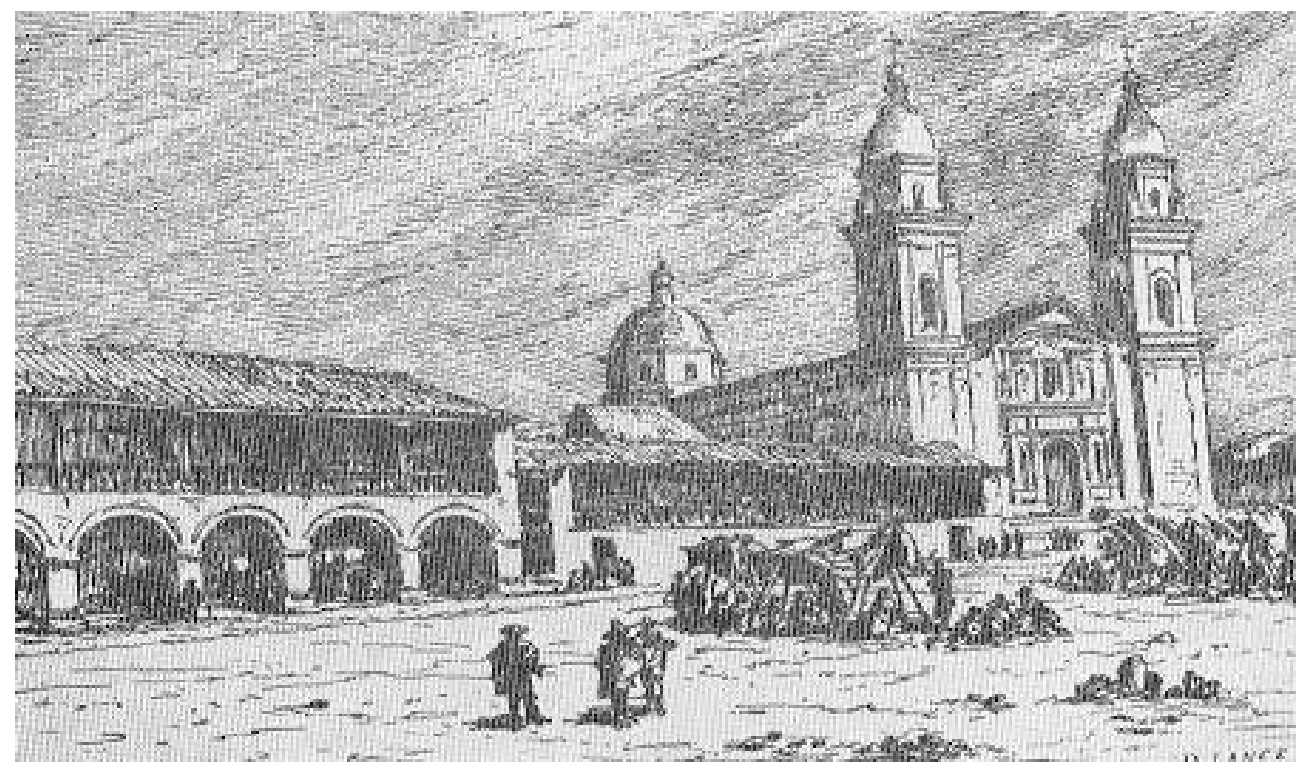

Figura 2. Apunte de Charles Winner sobre la Plaza de Jauja hacia 1875. (Recuperado de Hurtado, s/f). 
La infraestructura primigenia del Palacio Municipal tenía balcones y arquerías, a través de la historia, no se ha realizado un estudio detallado sobre el proceso que ha implicado su construcción. Solo circulan versiones orales disímiles que indican que se construyó hacia finales del siglo XIX o hacia la segunda década del XX. En el primero de los casos se dice que realizada hacia el año 1889. (Hurtado).

La segunda versión indica que el Municipio se habría construido en 1901, pero esta sería la restauración del local municipal que, posteriormente fuera demolido (Hurtado).

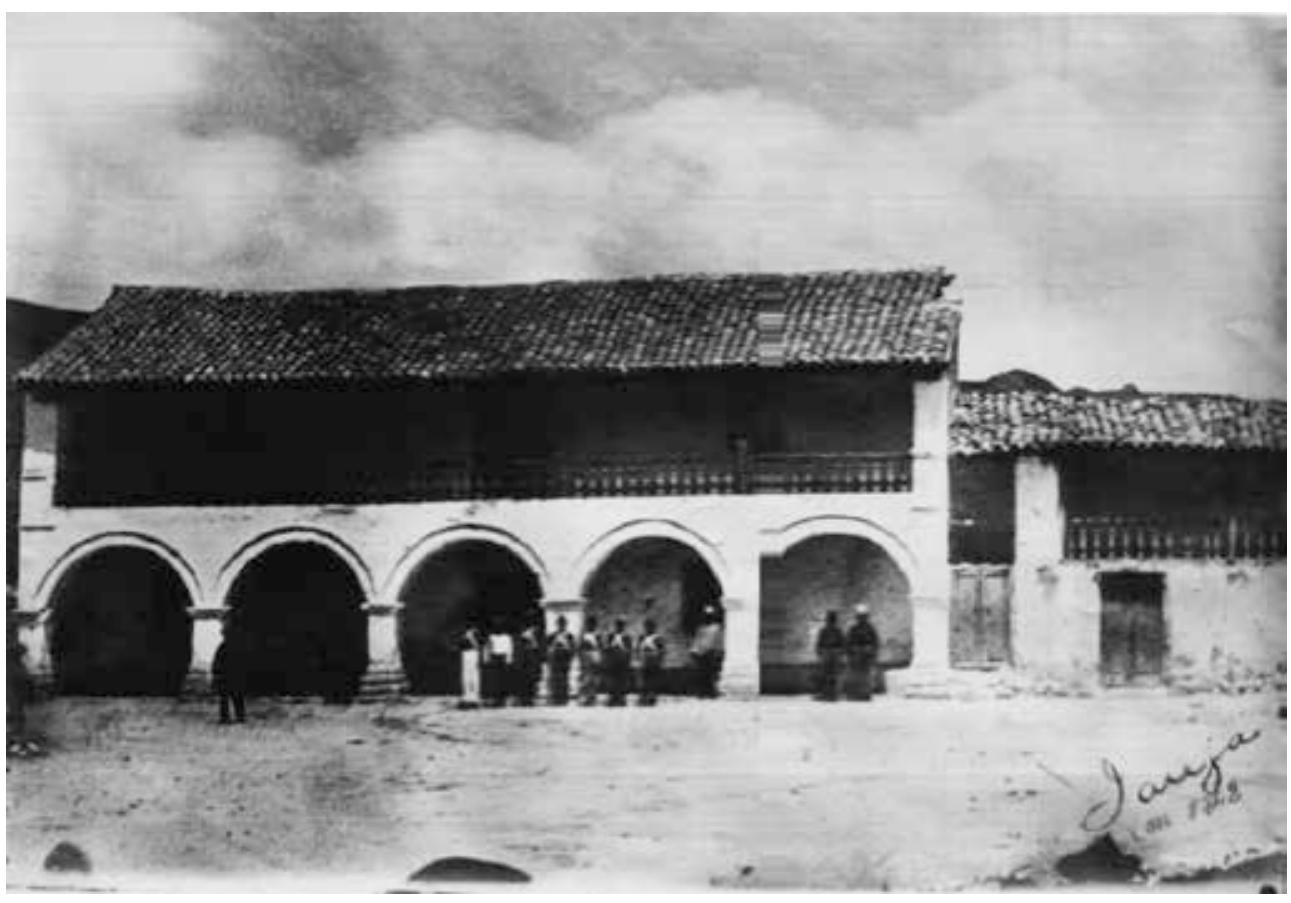

Figura 3. Antiguo Cabildo de Jauja que fue sustituido por la edificación actual del Municipio - fotografía de mediados del siglo XIX. (Hurtado, s/f)

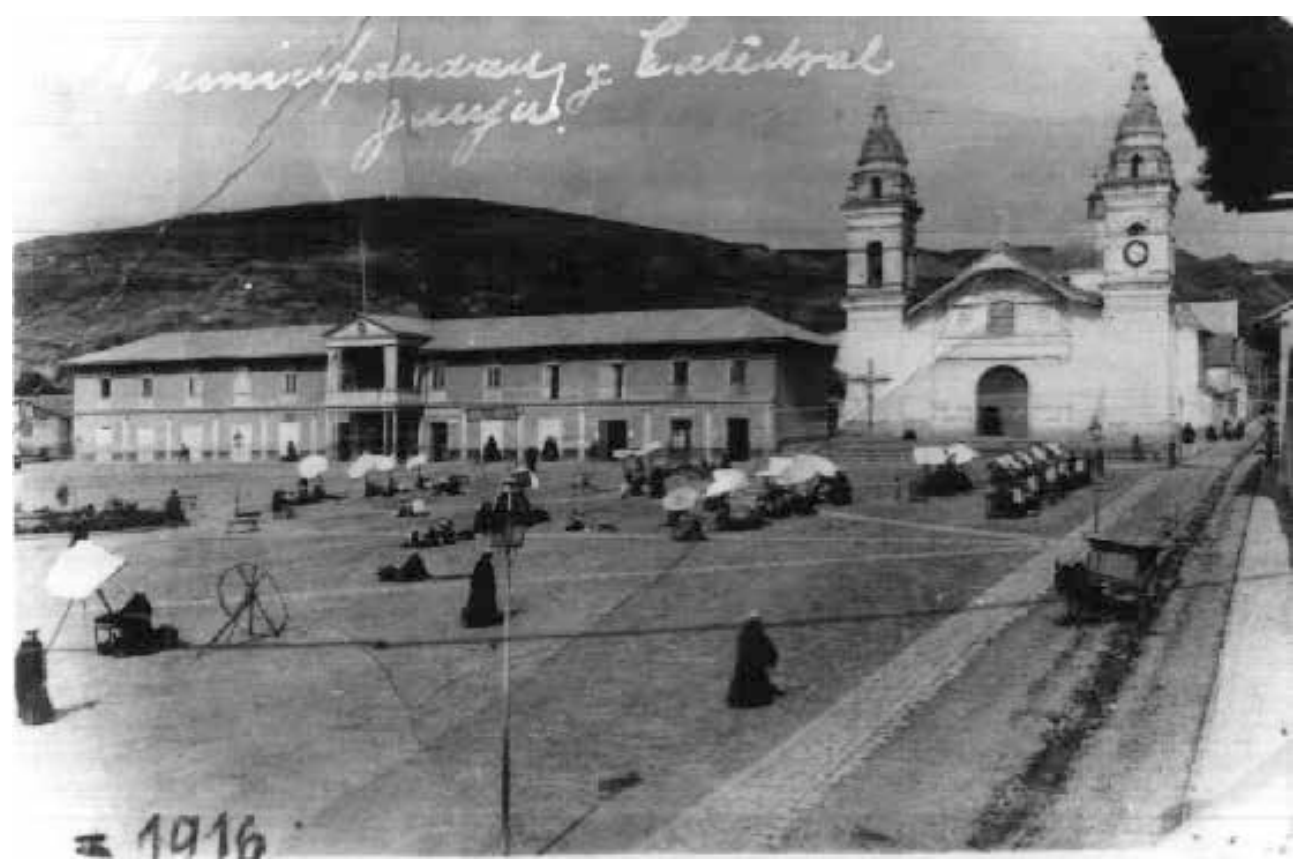

Figura 4. La Plaza de Armas hacia 1916. (Recuperado de Hurtado, s/f). 
Hacia el año 1916 la plaza seguía siendo una pampa, un espacio abierto, en la cual se realizaban las corridas de toros. La plaza era de tierra, salvo el borde, donde existía una pequeña pavimentación. El edificio donde se emplazaba el antiguo Cabildo colonial fue derruido y reemplazado por otra estructura, que es la que ahora existe y donde funciona la Municipalidad Provincial de Jauja. Igualmente, la plaza se podía definir como un "espacio femenino", en el sentido de que estaba ocupado por vendedoras que, al parecer, no necesariamente en días de feria, se instalaban ahí a ofrecer sus productos. (Hurtado).
La infraestructura de la Municipalidad Provincial de Jauja, habría sido construida entre los años 1907 a 1909, se encuentra documentada en el Archivo Regional de Junín, Sección Municipalidad Provincial de Jauja, Paquete 1 (Hurtado). Esta nueva construcción reemplazó el antiguo Cabildo colonial, y de acuerdo a información oral registrada, el nuevo local se erigió a semejanza de un ayuntamiento de España. Esta información concuerda, además, con el proceso de renovación urbana por el cual se construyeron la mayoría de casas de dos pisos con balcones antepecho y patio que caracterizan la estructura urbana de la ciudad (Hurtado).

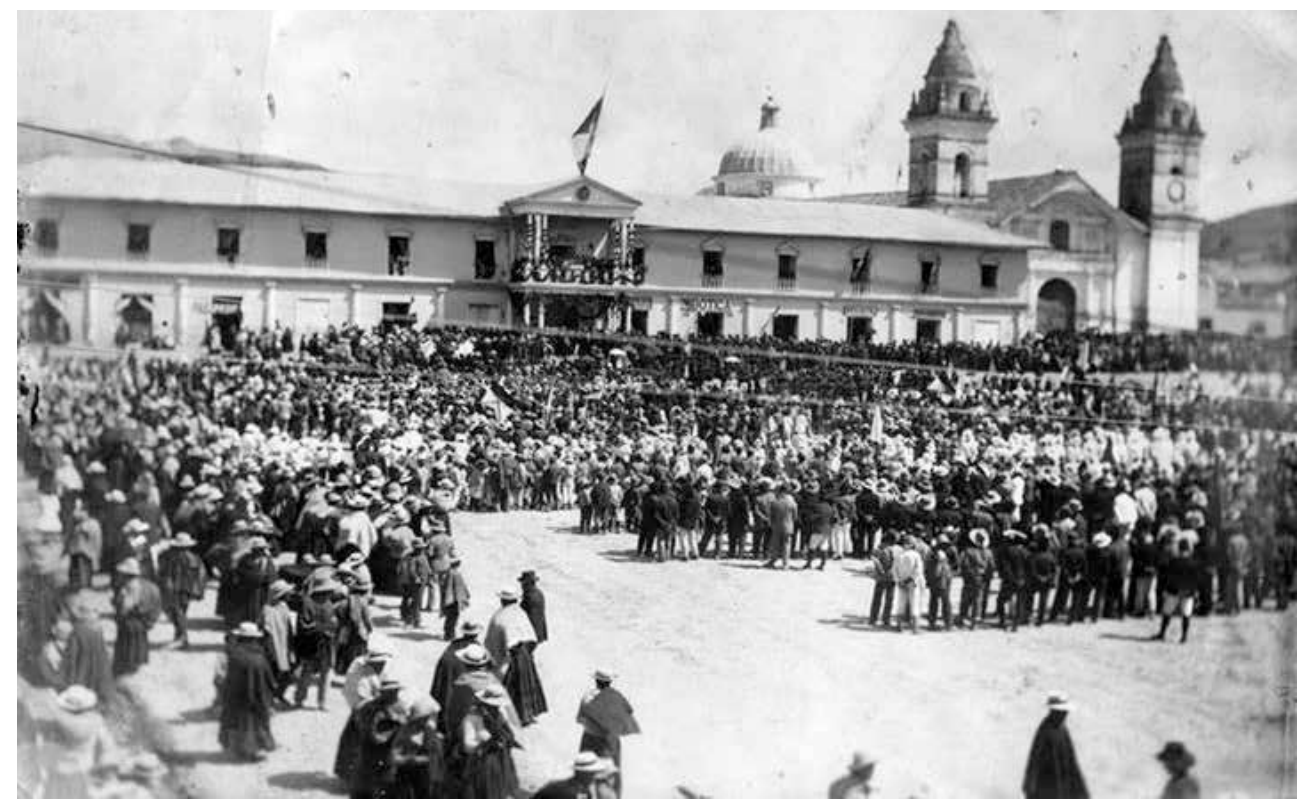

Figura 5. Plaza de Armas de Jauja en el año 1920 aproximadamente. (Recuperado de https://www.facebook.com/jaujaenblancoynegro/photos/a.18946110443539 4.40668.189348324446672/562417570473077/?type=3\&theater)

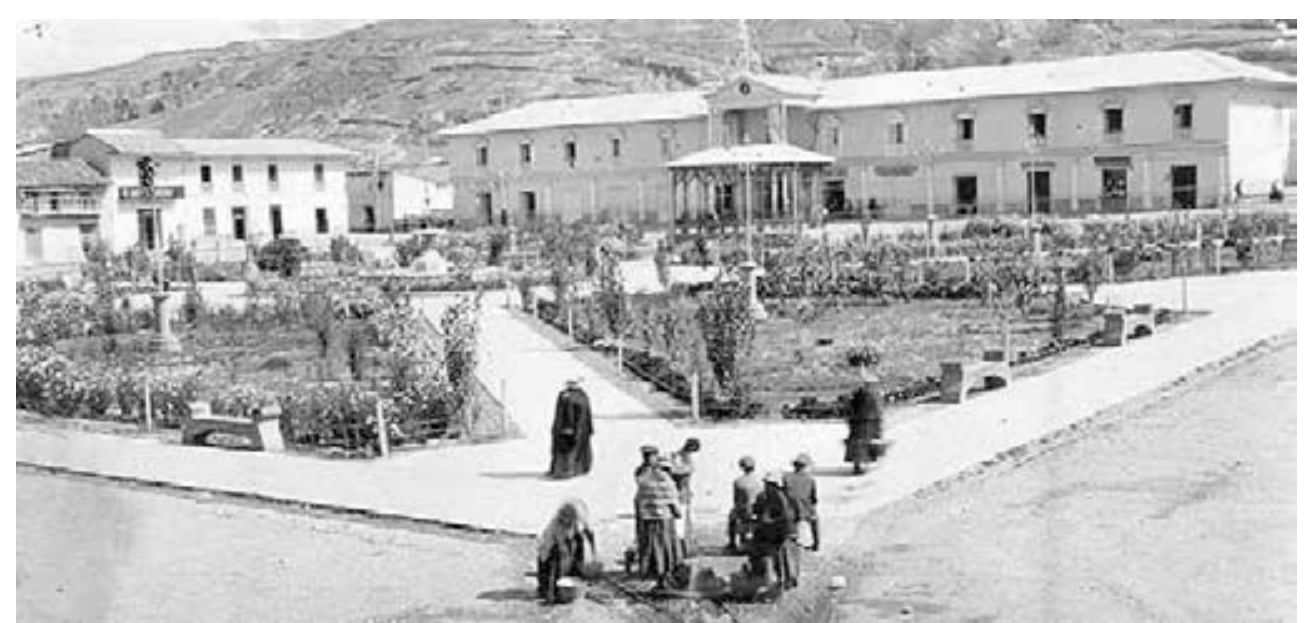

Figura 6. Detalle de la Plaza de Armas después de 1921. (Recuperado de Hurtado, s/f). 
Para el año 1921, la Plaza contaba con jardines, bancas, veredas una pileta al centro. La pavimentación de la Plaza data del año 1954, cuando se pavimentó la mayoría de las calles de Jauja que hasta ese momento eran empedradas. Desde esta fecha hasta la actualidad ha habido una diversidad de intervenciones en la plaza tales como: tala de árboles, anfiteatros techados y hundidos (sin utilidad), enrejado de los jardines, estatuas, losetas en las veredas, entre otros. (Hurtado).

Hacia el año de 1989, se realizó la obra de restauración de la Municipalidad Provincial de
Jauja con recursos propios del municipio. Para esa época la fachada del local estaba a punto de derrumbarse como consecuencia de los continuos atentados terroristas que asolaban al país.

En la actualidad, el local de la Municipalidad Provincial de Jauja se encuentra ubicado en la misma Plaza de Armas, al costado de la Iglesia Matriz. Es uno de los edificios singulares más importantes del ámbito local y está asociado a la identidad de los jaujinos en sus diferentes formas que lo han visto como parte de la ciudad desde que han nacido, la misma que es diferente a la original.

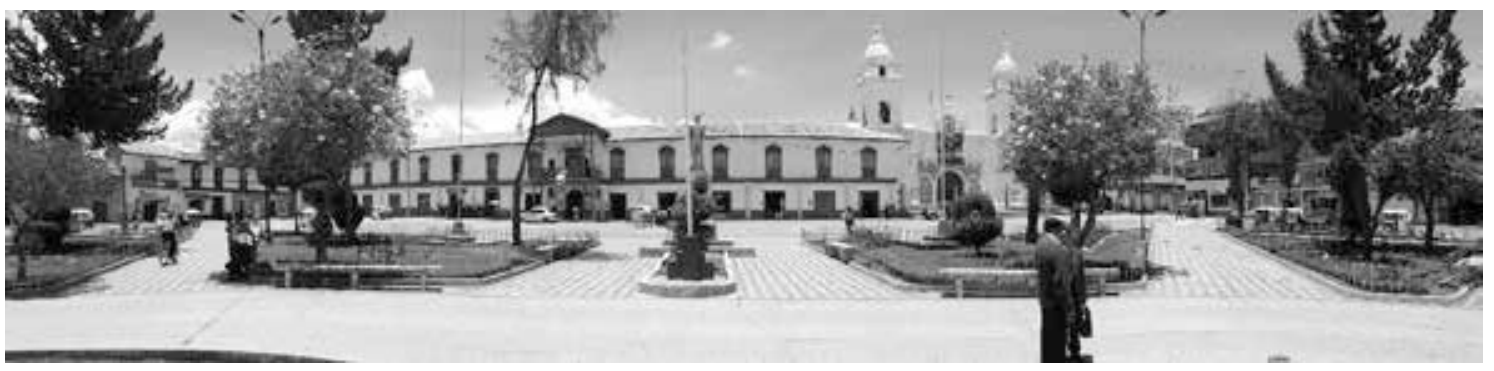

Figura 7. Fachada principal de la Municipalidad Provincial de Jauja, vista desde el Jr. Bolognesi. (Fotografía: Ana María Lebrún A.)

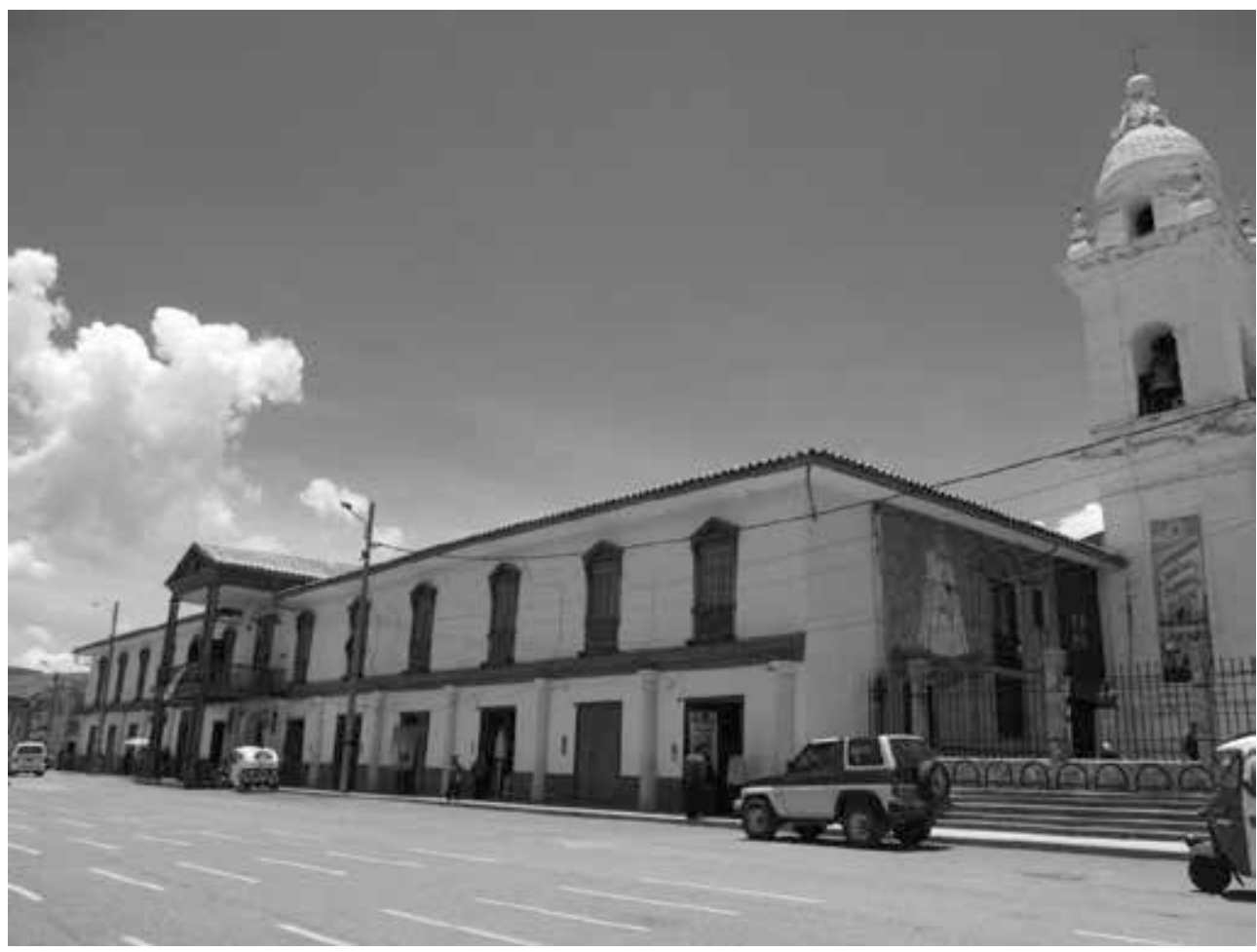

Figura 8. Fachada principal de la Municipalidad Provincial de Jauja, vista desde el Jr. Grau. (Fotografía: Ana María Lebrún A.) 


\section{AMBIENTES PARA EL CENTRO DE INTERPRETACIÓN}

Para el Centro de Interpretación de la Diversidad Cultural de Jauja se ha previsto utilizar ambientes del primer piso del local de la Municipalidad Provincial de Jauja, El fin es revalorar el carácter plural de la identidad propia de la comunidad jaujina en su doble dimensión de proceso evolutivo y fuente de expresión, creación e innovación.

Para la programación de áreas, la determinación de las zonas y ambientes ha sido planteada de acuerdo a las necesidades y funciones propias para el buen desarrollo de las actividades culturales que se realicen en esta institución cultural y educativa en Jauja.



Figura 9. Ambientes del primer piso de la Municipalidad Provincial de Jauja, destinados para el Centro de Interpretación de la Diversidad Cultural de Jauja. (Propuesta: Ana María Lebrún A.)

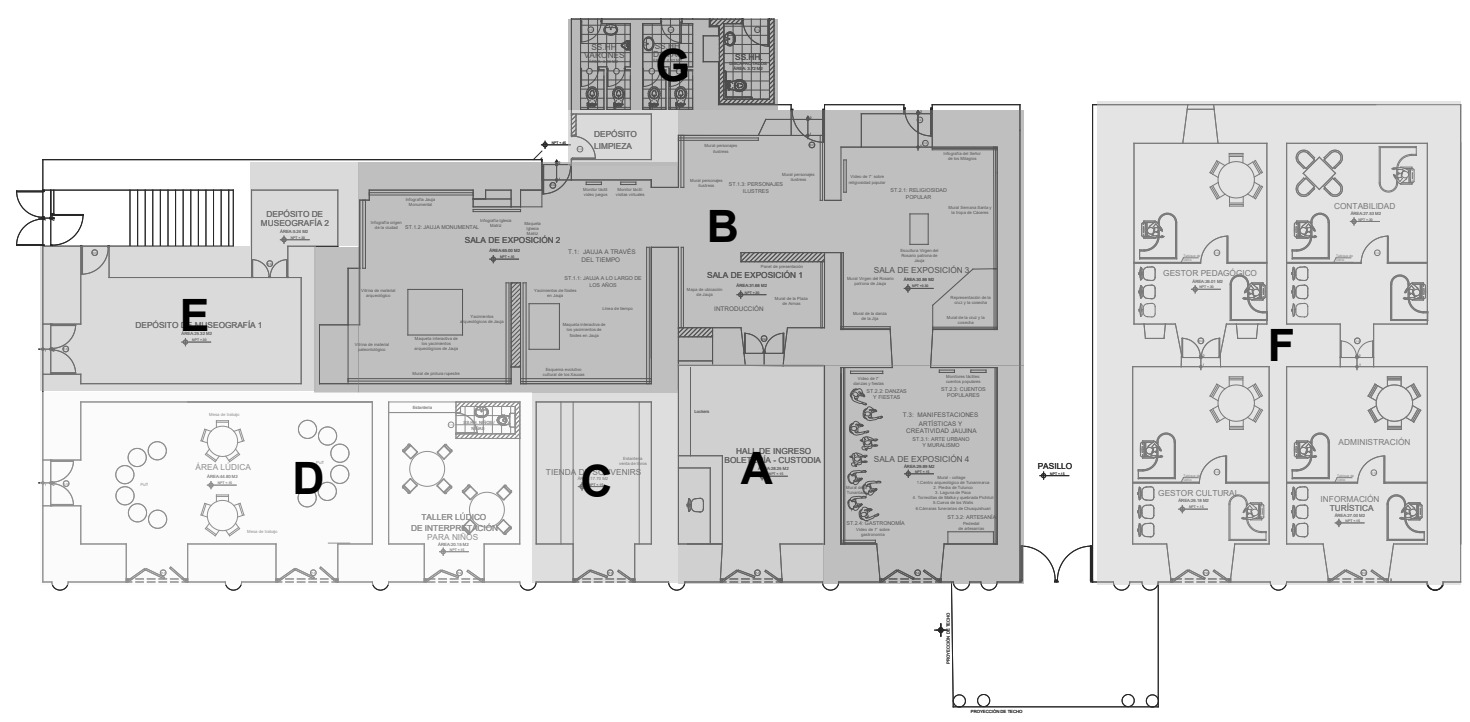

Figura 10. Distribución de ambientes: A. Recepción, hall de ingreso, informes. B. Salas de exposición. C. Tienda de souvenirs. D. Talleres lúdicos. E. Depósito de museografía. F. Oficinas administrativas. G. Servicios higiénicos. (Propuesta: Ana María Lebrún A.) 
Tabla 1

Cuadro de áreas del Centro de Interpretación. (Elaborado por Ana María Lebrún A.)

\begin{tabular}{|c|c|c|}
\hline \multicolumn{3}{|c|}{ PROGRAMACIÓN DE ÁREAS } \\
\hline \multicolumn{3}{|c|}{ ZONA COMÚN } \\
\hline AMBIENTE & UBICACIÓN & ÁREA ÚTIL \\
\hline Recepción/hall de ingreso/informes/boletería/custodia & Primer piso & $23.24 \mathrm{~m} 2$ \\
\hline SS. HH. damas & Primer piso & $4.53 \mathrm{~m} 2$ \\
\hline SS.HH. caballeros & Primer piso & $4.62 \mathrm{~m} 2$ \\
\hline SS.HH. discapacitados & Primer piso & $3.72 \mathrm{~m} 2$ \\
\hline \multicolumn{2}{|l|}{ SUB TOTAL ZONA COMÚN } & $36.11 \mathrm{~m} 2$ \\
\hline \multicolumn{3}{|c|}{ ZONA ADMINISTRATIVA } \\
\hline AMBIENTE & UBICACIÓN & ÁREA ÚTIL \\
\hline Oficina del gestor cultural y asistente & Primer piso & $24.86 \mathrm{~m} 2$ \\
\hline Oficina del gestor pedagógico y asistente & Primer piso & $23.76 \mathrm{~m} 2$ \\
\hline Administración y asistente de administración & Primer piso & $24.54 \mathrm{~m} 2$ \\
\hline Archivo y depósito de útiles de oficina & Primer piso & $23.65 \mathrm{~m} 2$ \\
\hline Depósito de limpieza & Primer piso & $5.19 \mathrm{~m} 2$ \\
\hline \multicolumn{2}{|l|}{ SUB TOTAL ZONA ADMINISTRATIVA } & $102.00 \mathrm{~m} 2$ \\
\hline \multicolumn{3}{|c|}{ ZONA DE EXPOSICIÓN } \\
\hline AMBIENTE & UBICACIÓN & ÁREA ÚTIL \\
\hline Sala de exposición 1 & Primer piso & $32.00 \mathrm{~m} 2$ \\
\hline Sala de exposición 2 & Primer piso & $60.38 \mathrm{~m} 2$ \\
\hline Área lúdica & Primer piso & $28.03 \mathrm{~m} 2$ \\
\hline Sala de exposición 3 & Primer piso & $20.70 \mathrm{~m} 2$ \\
\hline Sala de exposición 4 & Primer piso & $23.91 \mathrm{~m} 2$ \\
\hline Depósito de museografía 1 & Primer piso & $25.58 \mathrm{~m} 2$ \\
\hline Depósito de museografía 2 & Primer piso & $6.09 \mathrm{~m} 2$ \\
\hline \multicolumn{2}{|l|}{ SUB TOTAL ZONA DE EXPOSICIÓN } & $196.69 \mathrm{~m} 2$ \\
\hline \multicolumn{3}{|c|}{ ZONA DE SERVICIOS COMPLEMENTARIOS } \\
\hline AMBIENTE & UBICACIÓN & ÁREA ÚTIL \\
\hline Tienda de souvenirs & Primer piso & $12.94 \mathrm{~m} 2$ \\
\hline $\begin{array}{l}\text { Taller lúdico de interpretación para niños + SS.HH. } \\
\text { niños/niñas }\end{array}$ & Primer piso & $18.79 \mathrm{~m} 2$ \\
\hline \multicolumn{2}{|c|}{ SUB TOTAL ZONA DE SERVICIOS COMPLEMENTARIOS } & $31.73 \mathrm{~m} 2$ \\
\hline
\end{tabular}

\section{EL GUIÓN MUSEOLÓGICO}

Teniendo en cuenta que el Centro de Interpretación parte de una arquitectura pre existente, el guion museológico desarrollado se diseñó pensando en los espacios destinados para su planteamiento. Es por eso que se investigó arduamente todas las aristas de la diversidad cultural de Jauja, que permitan desarrollar la magnificencia de su historia y legado cultural para las generaciones actuales y venideras. Por su relevancia social es un hito que permitirá a todos los visitantes locales, regionales, nacionales $e$ internacionales que visiten esta institución cultural. 


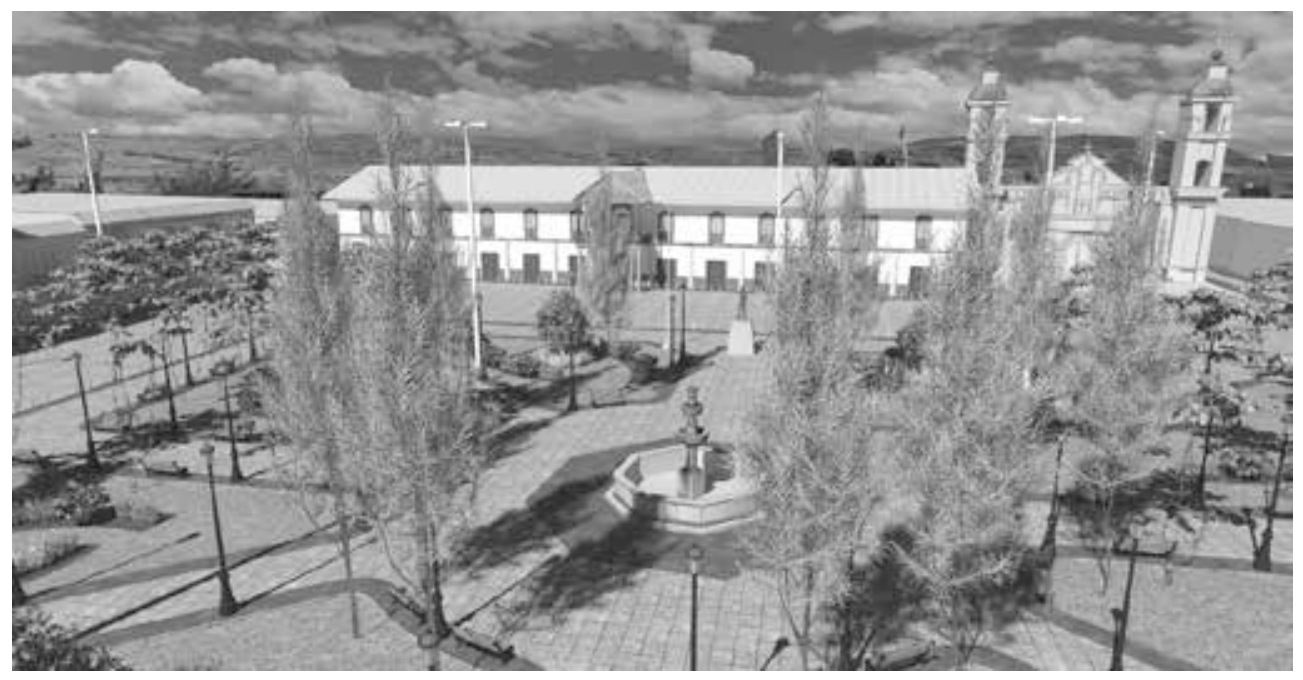

Figura 11. Vista 3D del local de la Municipalidad Provincial de Jauja visto desde la Plaza de Armas. (Propuesta: Ana María Lebrún A.)

Tabla 2

Relación de temas y subtemas a desarrollarse en el Centro de Interpretación de la Diversidad Cultural de Jauja. (Elaboración: Ana María Lebrún A.).

\section{CENTRO DE INTERPRETACIÓN DE LA DIVERSIDAD CULTURAL DE JAUJA EJE TEMÁTICO 1: JAUJA A TRAVÉS DEL TIEMPO}

Subtema 1.1: Jauja a lo largo de los años

Subtema 1.2: Jauja monumental

Subtema 1.3: Personajes ilustres

\section{EJE TEMÁTICO 2: CULTURA VIVA}

Subtema 2.1. Religiosidad popular

Subtema 2.2: Danzas y fiestas

Subtema 2.3: Cuentos populares

Subtema 2.4: Gastronomía

\section{EJE TEMÁTICO 3: MANIFESTACIONES ARTÍSTICAS Y CREATIVIDAD JAUJINA}

Subtema 3.1: Arte urbano y muralismo

Subtema 3.2: Artesanía

\section{EJE TEMÁTICO 1: JAUJA A TRAVÉS DEL TIEMPO}

\section{Jauja a lo largo de los años}

Desde las primeras crónicas de Jauja en los siglos XVI, XVII y XVIII se precisa que la ciudad era "un valle muy hermoso, muy vistoso, delicioso y placentero, con el aire templado y sereno" (Gobiernos Regional de Junín, 2010, p. 22). Existen indicios de ocupación humana en la región circundante a Jauja entre los siete mil y seis mil años a. C. El antecedente preinca más importante en la historia de Jauja es el grupo étnico denominado Xauxa
(1000 d.C. a 1460 d. C.), los mismos que se establecieron en el valle de Yanamarca, con centros ceremoniales como Tunanmarca, Hatunmarca, Llamaq Shillon y Huajlasmarca (Gobierno Regional de Junín, 2010).

Los Xauxas, se encontraban en proceso de crecimiento, el mismo que fue interrumpido cuando fueron conquistados por los incas, sometiéndolos de manera pacífica y violenta. Luego de la conquista, establecieron un centro administrativo denominado Hatun Xauxa, ubicándose en el territorio de los Xauxa, cerca del límite de los Huanca, en el valle del Mantaro (Gobierno Regional de Junín). 
A la llegada de los españoles a la ciudad de Jauja en marzo de 1533, pasados unos meses, en octubre del mismo año realizaron lo que se conoce como "la fundación a medias de Jauja", esto debido a que, a pesar de haberse realizado el acto de fundación y haberse designado Cabildo y Teniente Gobernador faltó lo principal, un número de vecinos que quisieran asentarse en la nueva ciudad. Recién en abril de 1534, cuando 53 españoles con el Gobernador a la cabeza expresaron su voluntad de vivir en ella, es a partir de ese momento que Jauja es la capital del Perú.

La ciudad de Jauja, como primera capital del Perú, tuvo una vida breve, debido a que en noviembre de 1534 los españoles la abandonaron y trasladaron la capital a Lima, fundando en enero de 1535 la Ciudad de los Reyes (Gobierno Regional de Junín).

\section{Jauja monumental}

Jauja, primera capital del Perú, nace como Pueblo de Indios con una plaza central y su trazo es a manera de tablero de ajedrez. En la plaza se destinan los lugares para la Iglesia, el Cabildo y las casonas para los vecinos más importantes. De acuerdo al Gobierno Regional de Junín (2010, p. 72):

En la primera fase evolutiva, alrededor del último tercio del siglo XVI, se construye una Capilla Primitiva de corte isabelino, típica de los templos coloniales rurales; un Cabildo que es de un solo piso, con cobertura a dos aguas de tejas, vanos pequeños y una puerta principal, donde destaca el revestimiento de cal sobre las paredes denotando importancia superlativa sobre las demás edificaciones. Las casas de los vecinos son pircas de adobe revestidas de barro de un solo piso con tejas y vanos diminutos de una o dos habitaciones. La plaza es un espacio amplio, donde se realizan los eventos sociales, económicos y legales.

Desde el año 1681 se tiene referencias de la Iglesia Matriz, ya que el cronista dominico Juan Meléndez, en su Tesoro verdadero de las
Indias, se refiere a las iglesias de Huancayo $y$ de Atun Xauxa (Iglesia Matriz) como las mejores del valle, y sus ornamentos, retablos y pinturas, se le compara con cualquiera de las mejores ciudades de Europa.

En Jauja se encuentra la primera iglesia mandada a construir por Francisco Pizarro, según el Ministerio de Cultura (2016), la Iglesia Matriz fue "diseñada en planta con forma de cruz latina, nave principal, crucero cubierto por una cúpula de estilo renacentista decorada con frescos al interior", considerada monumento por el Instituto Nacional de Cultura (actualmente Ministerio de Cultura). Igualmente Burga, J.; Moncloa, C.; Perales, M.; Sánchez, J. y Tokeshi, J. (2014) consideran que la arquitectura de la Iglesia Matriz es entre virreinal y republicana, la misma que se yergue en la parte alta de la plaza.

La segunda etapa evolutiva se aprecia con el cambio de la arquitectura existente de la iglesia y el Cabildo, ya que estos se transforman, siendo el equipamiento municipal una infraestructura de dos pisos y dos cuerpos con estructura de piedra y adobe, con arquerías pétreas y balcón corrido en el segundo piso. La capilla primitiva al ser transformada en la Iglesia Matriz se convierte en una iglesia más amplia (Gobierno Regional de Junín).

La tercera etapa es la actual imagen que presenta la Iglesia Matriz como una edificación de estilo neoclásico y la Municipalidad Provincial de Jauja. Progresivamente, la Plaza de Armas fue tornándose en un espacio con áreas verdes, con su pileta central tradicional, vías empedradas, faroles, bancos, entre otros.

\section{EJE TEMÁTICO 2: CULTURA VIVA}

Jauja cuenta con una variada y compleja cultura popular y patrimonio vivo. Cada distrito tiene una fiesta en particular. El ciclo festivo en Jauja se encuentra fuertemente asociado a la devoción católica de la zona. En el ámbito urbano la religiosidad popular se manifiesta a partir de la Fiesta Patronal de Jauja en homenaje a la Virgen del Rosario, la patrona de la ciudad y la procesión del Señor de los Milagros, organizada por la Hermandad 
del Señor de los Milagros de Jauja, inaugurada el 27 de octubre de 1953. Entre las danzas y fiestas más importantes por la participación de los jaujinos, estas son el Carnaval Jaujino y la Tunantada que se baila en el distrito de Yauyos.

\section{Religiosidad popular}

La festividad de la Virgen del Rosario Patrona de Jauja, no cuenta con información sobre la manera como se desarrollaba la festividad durante la colonia. Sin embargo, se sabe por documentación existente en diversos archivos, que existía una cofradía del Rosario en Jauja, a la que la élite, ya sea indígena o española, entregaba diversos tipos de donaciones, principalmente tierras de pan llevar. La importancia de la veneración y devoción rosariana en Jauja se comprueba al ver que, en los testamentos otorgados en aquella época, además de pedirse en gran mayoría como intercesora a la Virgen María, se pedía explícitamente ser enterrados a los pies del altar de la Virgen del Rosario de Jauja² .

Es la patrona de la ciudad de Jauja, se le celebra el primer domingo de octubre de todos los años y los días subsiguientes. Se realizan misas, novenas y procesiones, ferias de panes y dulces jaujinos. Todo con un marco de banda musical, pandillada y baile general.

Todos los años la imagen del Señor de los Milagros es venerada por los fieles católicos de Jauja, momento en el cual la población elabora hermosas y artísticas alfombras florales, donde la imagen descansa en ellas para recuperar fuerzas y así seguir su recorrido visitando las calles, casas, instituciones públicas y privadas. Con júbilo, entusiasmo y alegría cada institución recibe la visita de esta venerada imagen para dar la bienvenida a la hermandad y sentir la bendición de la reverenciada imagen que visita cada año los principales jirones y avenidas de la ciudad.

La feligresía jaujina, junto a la hermandad, las cantoras y las sahumadoras siguen a la imagen de inicio a fin, muchas veces enfrentándose al clima por las lluvias torrenciales que suelen desarrollarse en el mes de octubre.

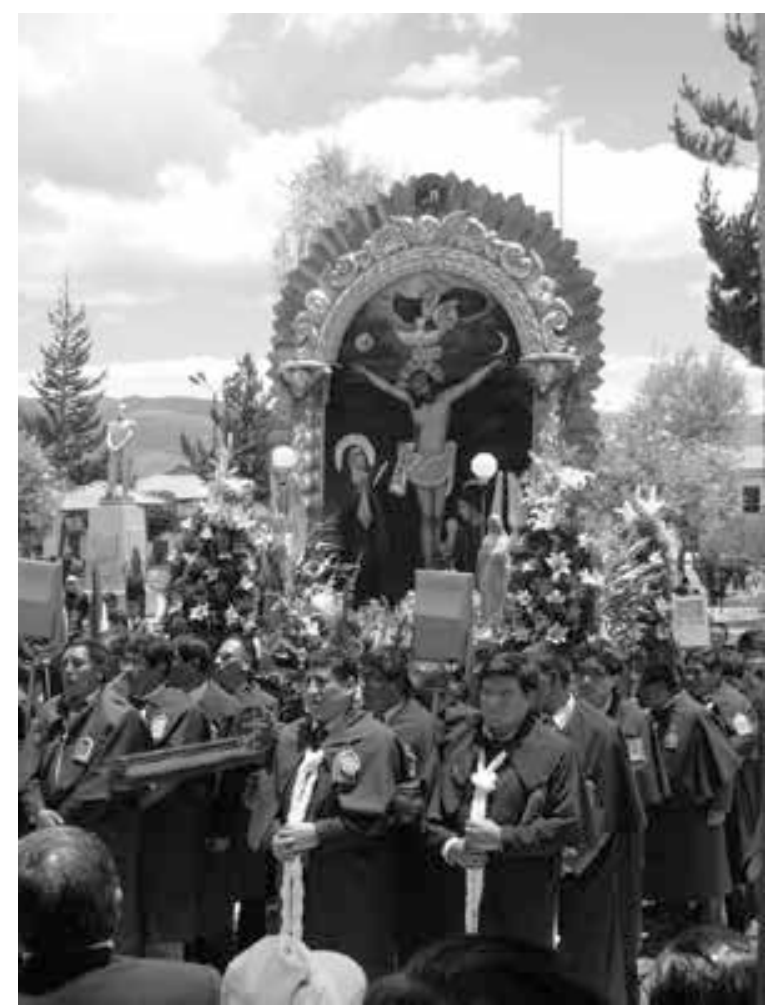

Figura 12. Procesión del Señor de los Milagros. (Fotografía: Ana María Lebrún A., 2015)

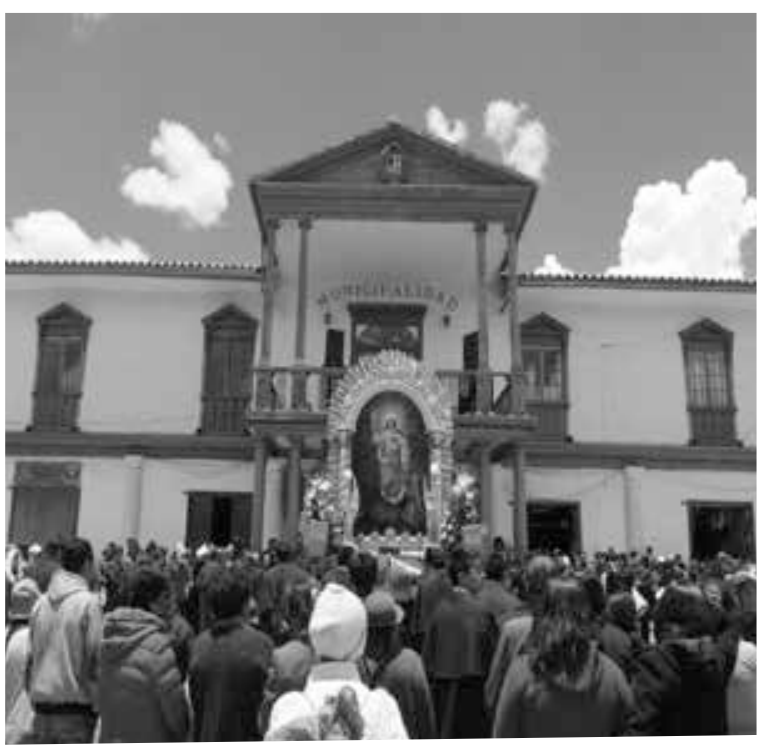

Figura 13. Procesión del Señor de los Milagros, en donde se aprecia la imagen de la Virgen de la Nube. (Fotografía: Ana María Lebrún A., 2015)

2 La Virgen del Rosario de Jauja. Escrito por Carlos H. Hurtado Ames. (Recuperado de http://pastoralyteologia.blogspot. pe/2012/10/la-virgen-del-rosario-de-jauja.html, 09 de diciembre de 2015). 


\section{Danzas y fiestas}

\section{La Tunantada}

La tunantada es una manifestación cultural de la provincia de Jauja, región Junín en el Perú que se ha manifestado como un proceso de transculturación, donde, a través de la danza, representa la evocación con una marcada esencia festiva, señorial y llena de vitalidad, que forma parte de la identidad cultural de los jaujinos.

Esta tradición se ha ido construyendo a lo largo de un proceso histórico, que se sigue manteniendo hasta nuestros días y que es celebrado durante el primer mes del año, debido a que enero era un mes ideal debido a que no había siembra, no había cosecha, existían reservas de lo acumulado del año anterior, dinero conseguido y ahorrado debido al trabajo realizado en las minas, alimentos almacenados, entre otros, siendo su punto de encuentro el populoso barrio de Yauyos.

Esta danza típica jaujina es una expresión simbólica de cultura popular, relacionada con la naturaleza social y la posición estructural de los individuos en un presente y con su pasado histórico y cultural. Entre los personajes que se encuentran en esta danza están el argentino, el boliviano, la cusqueña, la huanca, la chupaquina, entre otros, que evidencia un carácter inclusivo, donde todas las sangres tienen la posibilidad de estar presentes, de auto representarse y de reconocerse mutuamente.

A partir de su origen y trayectoria a través de tiempo, esta danza típica se viene documentando de manera fidedigna por los medios digitales. En ella la comunidad jaujina participa activamente para preservar esta tradición.

\section{Carnavales de Jauja - El Cortamonte}

El carnaval jaujino es pausado, sobrio, elegante, rítmico, pedante, como el espíritu del jaujino, afirma el historiados José Oregón Morales.

Cada año, la población de Jauja se organiza para celebrar a lo grande los carnavales; desde el vestuario elegante donde las mujeres visten: lliclla, monillo, faldellín, sombrero de paja, pañuelo, medias de nylon, zapatos de charol, y tacos altos, aretes y prendedor de oro, al puro estilo, garbo, elegancia y belleza jaujina. Mientras que el varón viste terno de color oscuro, camisa, corbata, poncho blanco de lana con rayas, negras, verdes o marrones, pañuelos de cuello, sombrero de paja, siempre con la galantería y la pedantería de los llamados "rajatablas" que muestran una sonrisa por su apodo durante siglos.

Es así como durante el mes de febrero se inician los carnavales, cada distrito y barrio se organiza desde la traída del árbol para ser plantado y bailar alrededor para luego cortarlo y festejar al nuevo padrino que pasará la fiesta al próximo año, costumbre que envuelve en el humor, la alegría, la irreverencia, la parodia y la elegancia de los que los pobladores y los visitantes.

Es costumbre que cuando una persona se ha comprometido a asumir un cargo festivo y fallece un pariente cercano suyo (padres, cónyuge o hijo), le es exonerado el gasto de ese año, pero se le exige asumir el cargo al año siguiente.

Si la persona o pareja comprometida no cumple su cargo festivo, recibe la crítica y burla general a través de unos muñecos que los representan y que se colocan en el monte o árbol que debían presentar, procediendo luego a quemarlos bajo los acordes de una marcha fúnebre. Además de esta sanción, se les excluye de todas las celebraciones institucionales.

"El cortamonte" son de aliso, eucalipto o guindo traído por los jóvenes que gustosos colaboran para trasladar al lugar donde será plantado para bailar alrededor del adornado árbol, costumbre que se da todo el mes de febrero en los barrios tradicionales de Jauja, Huarancayo, Panamericano, El Porvenir, La Libertad, Cruz de Espinas, Huaccllas, Yauyos, Marco y otros.

Antes de iniciar la danza alrededor del monte el padrino da el primer hachazo, posteriormente los invitados. Durante el baile se invita la chicha de jora y licor de caña, al compás de la sentida y nostálgica muliza, el huayno carnavalesco 
y la pandillada jaujina, interpretadas por reconocidas orquestas típicas que saben de la sensibilidad del jaujino deleitan con su música a los danzantes ${ }^{3}$.

\section{Cuentos populares}

Selección de relatos orales conservados por la tradición oral del Valle del Mantaro, transmitida por la milenaria cultura andina y cuyos sustratos ideológicos y lingüísticos acercan a una riquísima fabulación que, no deja de tener un gran caudal de resistencia aborigen a la compulsiva imposición cultural.

Los cuentos populares seleccionados son los siguientes:

- El alma que se fue sin vengarse

- Un alma que paga bien con bien

- La cabeza enamorada

- La leyenda del "quic - quic"

- Un condenado enamorado

- Una condenada por bruja

- La bruja y la huachgua

- La bruja y un muchacho cazador

- Aventura y muerte de un cura

- Un justo por cuatro pecadores

\section{Gastronomía}

La variedad gastronómica en Jauja es abundante, sobresalen los caldos como la patasca que contiene maíces, retazos de panza, tripa y charqui; el umancaldo que tiene un aromático sabor a pellejo tostado, acompañado de papas cocidas; el chupe verde con trozos de queso, huevo y papas combinados con hierbabuena y culantro y; el patachi, sopa de trigo con habas y pedazos de charqui (carne seca) y carán (pellejo de cerdo).

Entre los platillos de fondo se encuentra la pachamanca (olla en la tierra) donde se combina la carne de carnero, cerdo o pollo con abundante huacatay y las humeantes habas, humitas y papas; el cuy en salsa de maní acompañado de papas o arroz cocido; el cuy shactado untado con ají panca y papa sancochada; la trucha en sus diversas presentaciones (al ajo, frita, arrebozada, a la parrilla o en ceviche); el chicharrón colorado y el carnero al palo. También están las humitas saladas y dulces.

Entre los dulces destacan la gelatina de pata, las mazamorras de caya (oca), chuño, durazno, níspero, guinda y maca. Entre los refrescos sobresale la chicha de jora con sus distintos estados de maduración, chicha de maní y de soya. También está el calientito, que es un mate con hierbas aromáticas, alcohol de caña, miel y jugo de limón, acompañado con alguna cachanga o los tradicionales picarones de zapallo.

\section{EJE TEMÁTICO 3: MANIFESTACIONES ARTÍSTICAS Y CREATIVIDAD JAUJINA}

\section{Subtema 3.1: Arte urbano y muralismo}

El arte urbano y muralismo es la incorporación del arte como parte integrante del espacio urbano, convirtiéndose en arte para todos. Con este planteamiento se pretende replantear la importancia de la ciudad en relación con el medio ambiente y de los habitantes con su entorno, para de esta manera generar identidad social.

\section{Subtema 3.2: Artesanía}

El distrito de Julcán muestra su arte a través de la zapatería por la calidad de su diseño y trabajo. El distrito de Molinos se distingue por conservar talladores en madera, donde aún perdura el arte de convertir el aliso en águilas, leones, labriegos o máscaras de danza, igualmente elaboran objetos de madera de uso utilitario, ceremonial o de adorno.

Otra actividad artesanal reconocida es la elaboración de pintorescos muñecos a croché y palito, que evocan los diferentes personajes de las danzas regionales como tunantes, jaujinas, chutos, tucumanos, huanquillas, chacranegros, etc. Las más demandadas son las jaujinas por su colorido y porte.

3 La Elegancia del Carnaval de Jauja. Por Lizzet Paz. (Recuperado de: http://blog.pucp.edu.pe/blog/sergio nunez/2010/04/05/ jauja-santa-cuarto-poder/, 09 de diciembre de 2015) 


\section{PROPUESTA MUSEOGRÁFICA}

La propuesta museográfica del Centro de Interpretación de Jauja es mediante un recorrido temático a través de una propuesta museográfica con elementos bidimensionales, tridimensionales y la utilización de las nuevas tecnologías.

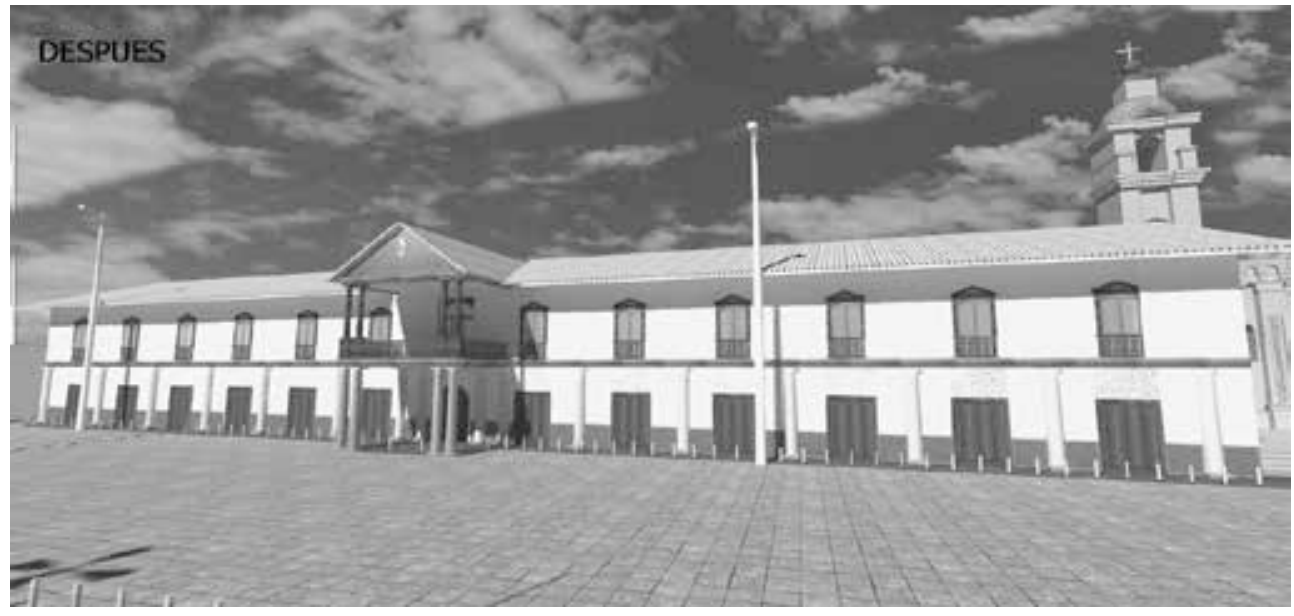

Figura 14. Vista 3D del local de la Municipalidad Provincial de Jauja.

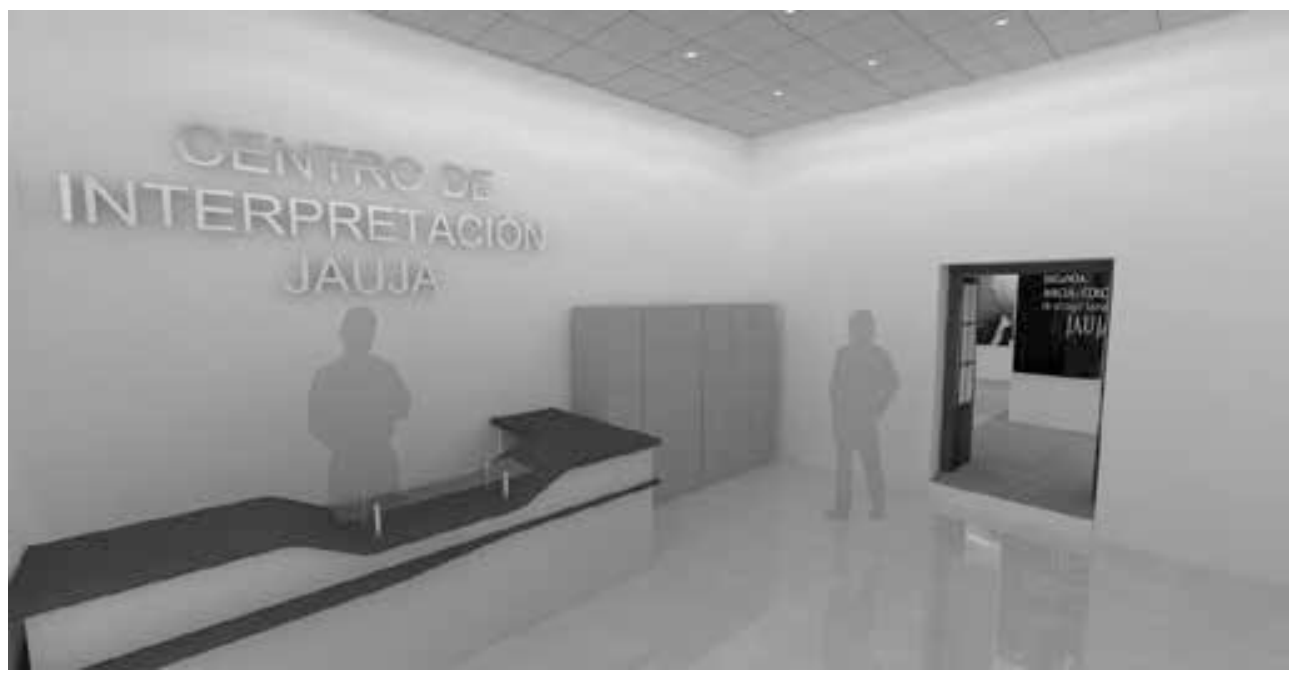

Figura 15. Vista 3D del hall de ingreso del Centro de Interpretación.

Toda la propuesta se encuentra compuesta por elementos bidimensionales que han sido desarrollados bajo una propuesta gráfica, a partir de fotografías, infografías y murales realizados por los propios artesanos jaujinos. El planteamiento tridimensional consta de maquetas, piezas réplicas de material paleontológico y arqueológico, maniquíes, esculturas, recreaciones, artesanías, entre otros y por la utilización de nuevas tecnologías mediante monitores táctiles con propuestas de juegos interactivos, cuentos, videos, documentales, entre otros.
La propuesta planteada sirve para que los visitantes puedan interactuar sin inconvenientes con el material planteado tales como: maquetas interactivas, videos a través de los televisores plasma y los monitores táctiles, que permite una manipulación sencilla y práctica. Se tiene en cuenta que el Centro de Interpretación está orientado al ámbito educativo y lúdico, a partir de una exposición activa y dinámica, con aplicaciones didácticas e interactivas, para la adquisición de conocimientos y el desarrollo de las capacidades creativas de los visitantes. 


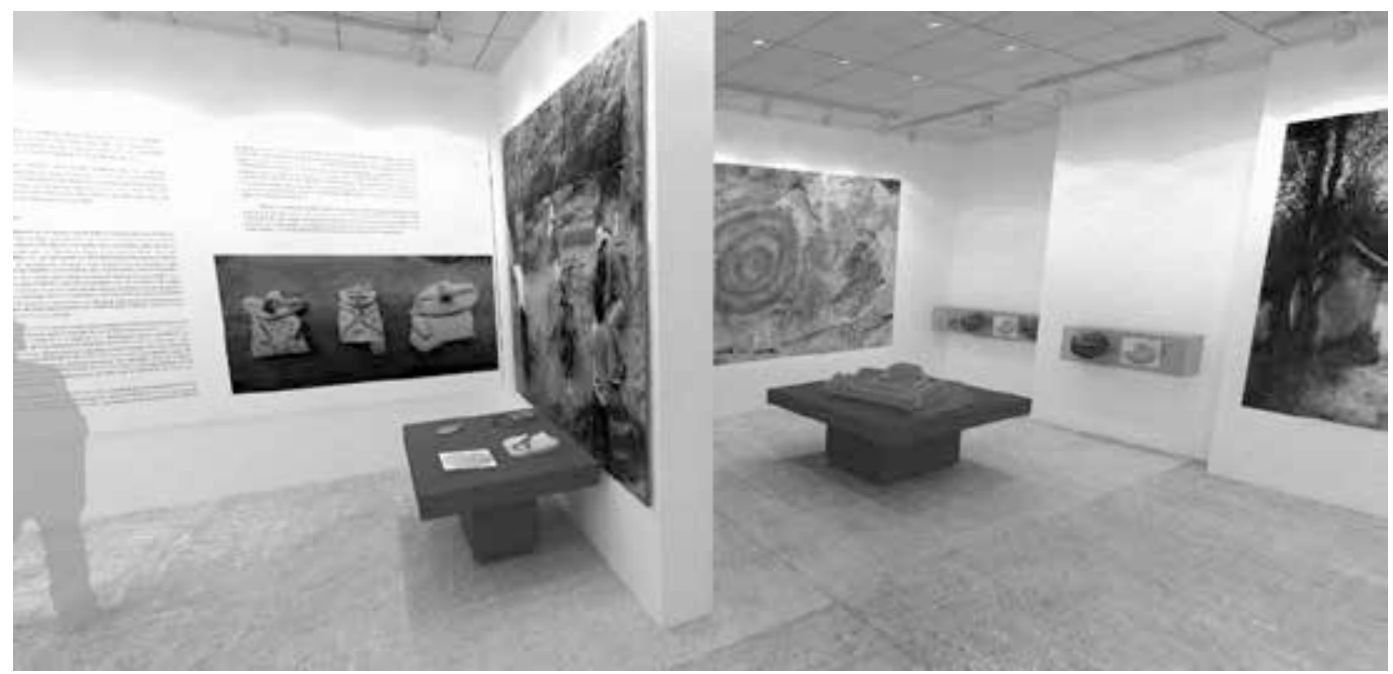

Figura 16. Vista 3D de la Sala de Exposición del Centro de Interpretación.

Para el Centro de Interpretación de la Diversidad Cultural de Jauja se ha planteado un área lúdica que es parte del componente intrínseco de las salas de exposición, para que reflexionen y se sensibilicen frente al material cultural y natural presentado en este espacio cultural, la misma que permite ejecutar acciones de apoyo de divulgación de la diversidad cultural de Jauja, interpretación y mediación entre los visitantes y el centro de interpretación. Para ello se contará con un gestor pedagógico que brindará un desarrollo metodológico para las actividades en general.

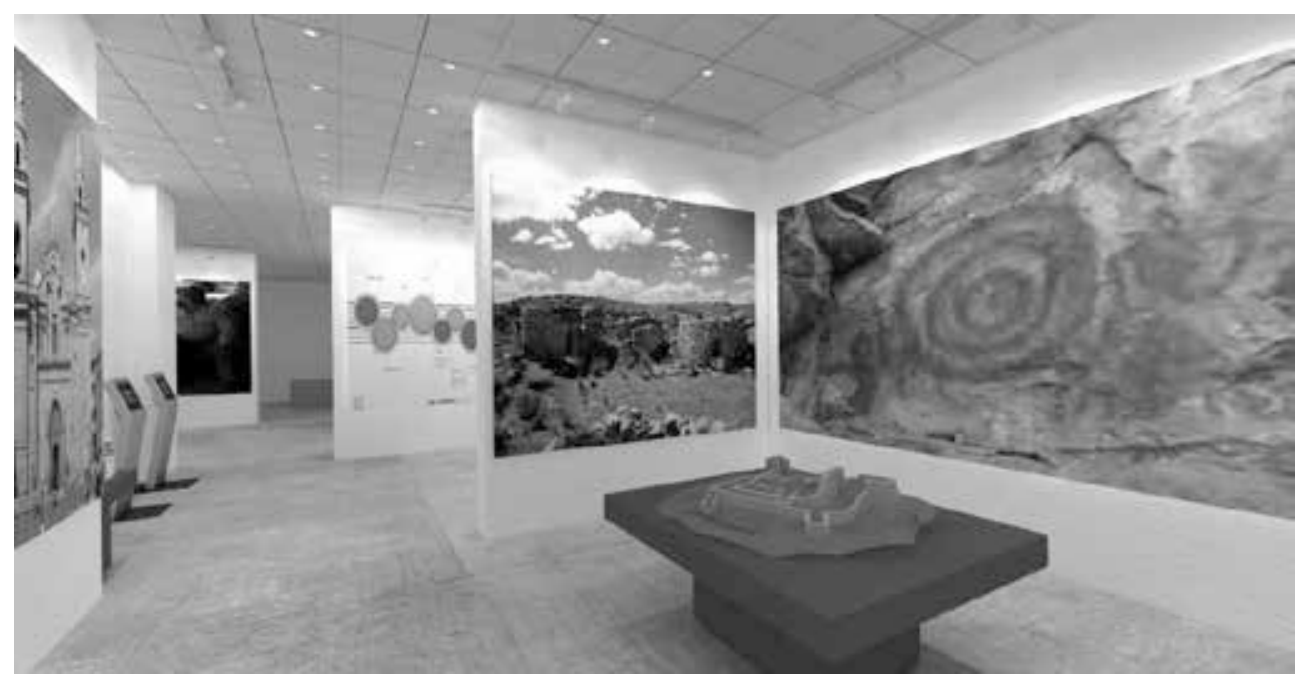

Figura 17. Vista 3D de la Sala de Exposición del Centro de Interpretación.

La labor educativa en el centro de interpretación, con el desarrollo de actividades dentro de la educación formal y no formal, permite que esta sea una experiencia significativa para los visitantes, a la vez de motivadora, vivencial y educativa, a fin de que la sociedad en su conjunto se acerque e interactúe con el conocimiento.

El área lúdica es un espacio exclusivamente para juegos didácticos e interactivos, donde se desarrollan talleres y actividades manuales, interactivas a través de la manipulación de piezas donde se incluyen imágenes y fotografías de las diversas fiestas y danzas tradicionales, lugares turísticos, personajes ilustres, entre otros. Este espacio está orientado a niños, adolescentes, jóvenes, adultos y adultos mayores. 


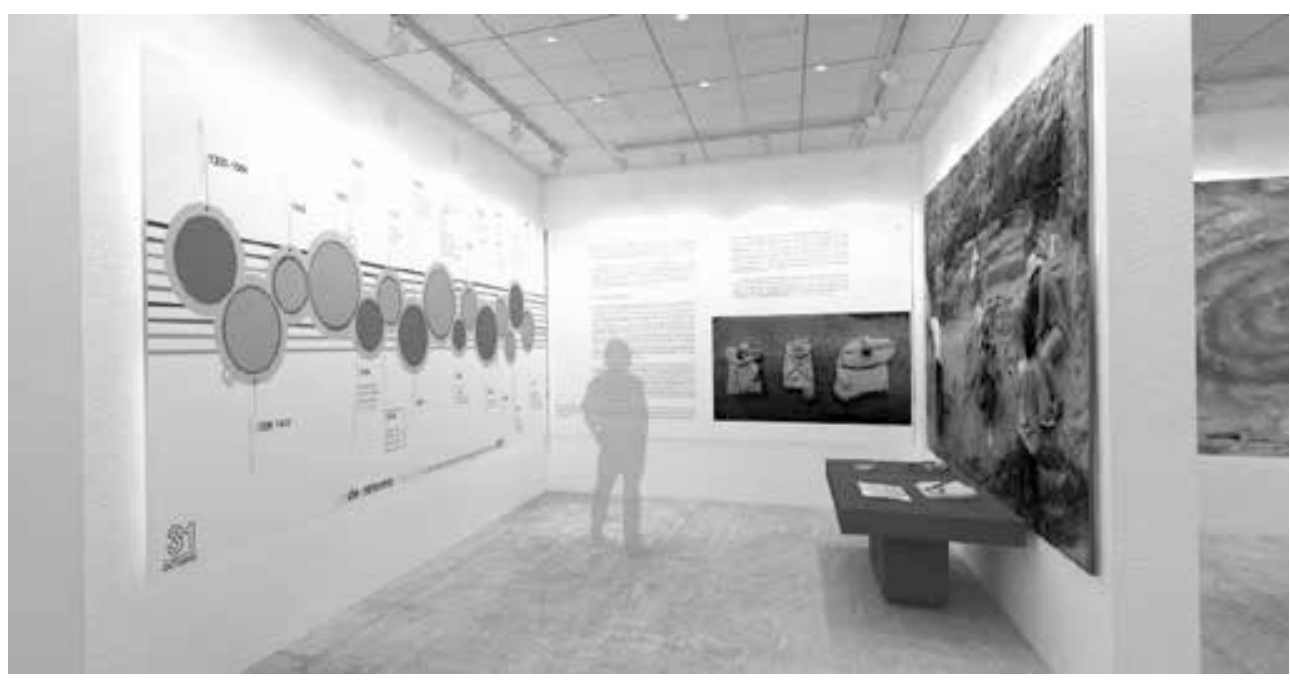

Figura 18. Vista 3D de la Sala de Exposición del Centro de Interpretación.

Finalmente, la iluminación museográfica se realiza mediante iluminación led, exclusivamente para resaltar todos los objetos, piezas paleontológicas y arqueológicas, ilustraciones, gráficas, murales, iconografías, maniquíes, entre otras que se exhibirán en el centro de interpretación.

\section{CONCLUSIONES}

El centro de interpretación de la diversidad cultural de Jauja pretende ser un eje turístico cultural de la ciudad, donde la población local y los visitantes nacionales y extranjeros que lleguen a la primera capital del Perú, encuentren en su cultura viva y folklore los ejes fundamentales de las costumbres, danzas, fiestas populares, centros arqueológicos $y$ lugares turísticos que hacen de Jauja un lugar atractivo para conocer y admirar su legado cultural a través de la historia.

Los espacios de exposición permanente, donde se han planteado los diversos ejes temáticos, contribuyen al desarrollo cultural y al reforzamiento de la identidad de la población en general, generando conciencia y sensibilización para el desarrollo integral, inclusivo y equitativo del legado cultural de Jauja.

El centro de interpretación, permite el diálogo intercultural y la creatividad cultural, introduciendoprocesos cognitivosyemocionales a los visitantes, mediante la interpretación y el respeto a la comunidad local. 


\section{REFERENCIAS}

Álbum: JAUJA con motivo de la celebración del IV Centenario de la Fundación Española de esta ilustre ciudad. (1934) Jauja, Perú: Casa Editora Orellana.

Bonilla, E. (2013) Jauja. Estampas de folklore. $2^{\circ}$ Ed. Lima, Perú.

Burga, J. Moncloa, C., Perales, M., Sánchez, J. y Tokeshi, J. (2014) Tradición y Modernidad en la Arquitectura del Mantaro. Huancayo, Perú: Universidad Continental de Ciencias e Ingeniería SAC.

Concha, G. (Compilador) (2010) Historia, Arquitectura y Urbanismo en el Valle del Mantaro. Huancayo, Perú: Universidad del Centro del Perú.

Espinosa, C. (1964) Jauja antigua. Lima, Perú: Talleres Gráficos P.L. Villanueva, S.A.

Gobierno Regional de Junín, Dirección Regional de Comercio Exterior y Turismo, Proyecto Jauja Monumental. (2010) Jauja. Pedacito de cielo. Huancayo, Perú: Región Junín.

Lebrún, A. (2015) La educación formal, no formal e informal: una tarea pendiente en los museos del Perú. Revista institucional CONSENSUS 20. Perú: Editorial UNIFÉ.

Mallma, A., Cáceres, L., Loayza, H. y Villanes, L. (1991) El escudo de Jauja: aportes para su esclarecimiento. Jauja, Perú: Centro de Estudios Histórico Sociales "Julio Espejo Núñez".

Ministerio de Cultura, Dirección Desconcentrada de Cultura de Junín (2016) Patrimonio Histórico Inmueble de Junín. Huancayo, Perú: Autor.

Mucha, F. (2015) Tunantada. Precisiones y Antología. Huancayo, Perú: Obregón Impresores SAC.

Municipalidad distrital de Yauyos. (2002) El Tunantero III. Kumu cuna cushicullashon chuspipa tullunta pinculluculcul. Jauja, Perú.

Perales, M., Villanes, L., Loayza, H., Cáceres, L., Rafael, L. (2015) Los Xauxas: sus orígenes. Hallazgos arqueológicos en San Juan Pata - Jauja. Jauja, Perú: Halckon Editores.

Rivera, E. (2012) Historia y leyenda de la tierra de Jauja. Lima, Perú: Fundación M.J. Bustamante de la Fuente.

Villanes, L., Loayza, H., Cáceres, L. (2009) Los Xauxas Territorio e Historia. Jauja, Perú: Industria Gráfica Obregón.

\section{Internet}

La Elegancia del Carnaval de Jauja. Por Lizzet Paz. (Recuperado de: http://blog.pucp.edu.pe/blog/ sergionunez/2010/04/05/jauja-santa-cuarto-poder/, 09 de diciembre de 2015)

La Virgen del Rosario de Jauja. Escrito por Carlos H. Hurtado Ames. (Recuperado de http:// pastoralyteologia.blogspot.pe/2012/10/la-virgen-del-rosario-de-jauja.html, 09 de diciembre de 2015) 
Tunanmarca. Luis Cáceres (Licenciado en Arqueología). (Recuperado de http://historiaenfotosperu. blogspot.pe/2010/09/tunanmarca.html, 09 de diciembre de 2015)

Fecha de recepción: 16-08-16

Fecha de aceptación: 21-10-16 